\title{
The unintended consequences in clinical research
}

\author{
Abe DeAnda, Jr, MD, ${ }^{\mathrm{a}}$ Vincent R. Conti, MD, ${ }^{\mathrm{a}}$ and Vincent G. Valentine, MD ${ }^{\mathrm{b}}$
}

\footnotetext{
From the ${ }^{\mathrm{a}}$ Division of Cardiovascular and Thoracic Surgery UTMB-Galveston, Galveston, Tex; and ${ }^{\mathrm{b}}$ Division of Pulmonary, Allergy and Critical Care Medicine University of Alabama - Birmingham, Birmingham, Ala. Disclosures: Authors have nothing to disclose with regard to commercial support.

Received for publication Sept 24, 2018; accepted for publication Sept 26, 2018; available ahead of print Nov 3, 2018.

Address for reprints: Abe DeAnda, Jr, MD, Division of Cardiothoracic Surgery, UTMB-Galveston, 301 University Blvd, Galveston, TX 77551 (E-mail: abdeanda@utmb.edu).

J Thorac Cardiovasc Surg 2019;157:285-6

$0022-5223 / \$ 36.00$

Copyright (C) 2018 by The American Association for Thoracic Surgery

https://doi.org/10.1016/j.jtcvs.2018.09.081
}

The contact of blood with an artificial surface such as the cardiopulmonary bypass (CPB) circuit ignites a systemic inflammatory response syndrome (SIRS) of varying degree. This spark activates the complement cascade and the release of cytokines and adhesion molecules, and most of the time this SIRS response is of little to no clinical consequence. It can explode into a cytokine storm with detrimental or devastating consequences; the lungs are not immune to these events and may be more susceptible to injury because of the period of relative ischemia during CPB when the perfusion of the lungs is reliant solely on the bronchial artery system. Additional risks or threats of lung injury include anesthesia, positive pressure ventilation, hypothermia, transfusions, and other activities that are routinely a part of cardiac surgery.

Measuring the level or degree of lung injury post-CPB can be challenging, especially when assessing the contribution of CPB itself on potential lung or multiorgan dysfunction. When examining surrogates as reported in the Society of Thoracic Surgeons database for 2017, for example, there are differences in mean and median ventilator times between on-pump (17.5 and 5.7 hours) and off-pump (13.2 and 4.9 hours) coronary artery bypass grafting. This approximate (and by no means statistical) comparison might have a fair number of reasons why ventilator times were longer for on-pump cases versus off-pump, but regardless whether these differences are statistically significant or not, these results are not surprising.

In this issue of the Journal, Gao and colleagues ${ }^{1}$ present a potential method of ameliorating the negative effect of CPB with the use of inhaled budesonide, a corticosteroid commonly used in the long-term management of asthma and chronic obstructive pulmonary disease. ${ }^{2}$ Patients presenting for cardiac surgery with $\mathrm{CPB}$ received budesonide or saline pre-CPB in a double-blinded randomized fashion using the nadir arterial oxygen tension/inspired oxygen fraction ratio (pulmonary flow reserve $[\mathrm{PFR}]$ ) as the primary end point in the blood loss volume.

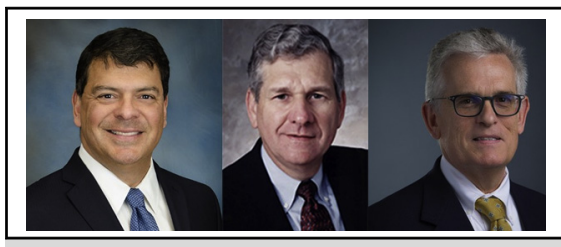

Abe DeAnda, Jr, MD, Vincent R. Conti, MD, and Vincent G. Valentine, MD

Central Message

Amelioration of lung injury secondary to a systemic inflammatory response due to CPB may be possible with inhaled steroids.

See Article page 272.

post-CPB period. A bronchoalveolar lavage (BAL) was performed before $\mathrm{CPB}$ and after sternal closure, and the fluid was analyzed for pro- and anti-inflammatory markers, including C-reactive protein, tumor necrosis factor- $\alpha$, interleukin 1 and 10, and complement.

Gao and colleagues ${ }^{1}$ found a significant decrease in median ventilator time (17.4 vs 20.7 hours, $P=.019$, budesonide vs placebo) and better respiratory performance as measured by the PFR in the postoperative period without a significant difference in clinical outcomes otherwise. With a generally accepted PFR greater than $150 \mathrm{~mm} \mathrm{Hg}$ at all time points for both groups, it appears that both had clinically acceptable oxygenation parameters. There were expected changes in biomarkers as well.

Prevention of injury (with inhaled budesonide) is preferable to treating the consequences of injury. However, in their eagerness to prevent injury, Gao and colleagues ${ }^{1}$ may have ignited an injury by sampling BAL fluid through the right channel of a double-lumen tube with an unspecified size of a Pentax bronchoscope (PENTAX Medical, Montvale, NJ). The authors may have lost sight of potential unintended consequences in this study design, and in the process, selective barotrauma or volu-trauma may have occurred in the left lung and its sequelae detected on the right. We might also conclude that budesonide dampens the injury related to obtaining BAL in both cohorts. Additional sources of injury could include the seemingly abnormal amount of blood and blood products transfused given the comparably low 
It remains unclear whether systemic steroids would have a similar effect on the response to SIRS in the setting of $\mathrm{CPB}$, and perhaps measuring blood rather than $\mathrm{BAL}$ markers of inflammation might have had gentler and meaningful consequences. Nevertheless, this study should spark some interest in the continuing quest to optimize the care of the patient on CPB.

\section{References}

1. Gao W, Li N, Jin ZH, Lv XQ, Cui XG. Effect of preoperative inhaled budesonide on pulmonary injury after cardiopulmonary bypass: a randomized pilot study. $J$ Thorac Cardiovasc Surg. 2019;157:272-84.

2. Stolz D, Hirsch HH, Schilter D, Louis R, Rakic J, Boeck L, et al Intensified therapy with inhaled corticosteroids and long-acting $\beta 2$-agonists at the onset of upper respiratory tract infection to prevent chronic obstructive pulmonary disease exacerbations. Am J Respir Crit Care Med. 2018;197:1136-46 